\title{
CORRECTION
}

\section{Correction to: The WOMAC score can be reliably used to classify patient satisfaction after total knee arthroplasty}

\author{
Lucy C. Walker ${ }^{1} \cdot$ Nick D. Clement $^{1} \cdot$ Michelle Bardgett $^{1} \cdot$ David Weir $^{1} \cdot$ Jim Holland ${ }^{1} \cdot$ Craig Gerrand $^{1}$. \\ David J. Deehan ${ }^{1}$
}

Published online: 11 April 2018

(c) European Society of Sports Traumatology, Knee Surgery, Arthroscopy (ESSKA) 2018

\section{Correction to: \\ Knee Surgery, Sports Traumatology, Arthroscopy \\ https://doi.org/10.1007/s00167-018-4879-5}

Unfortunately, Fig. 1 in the original article contained incorrect information. Hereby, the correct figure is published and the authors apologise for the inconvenience.

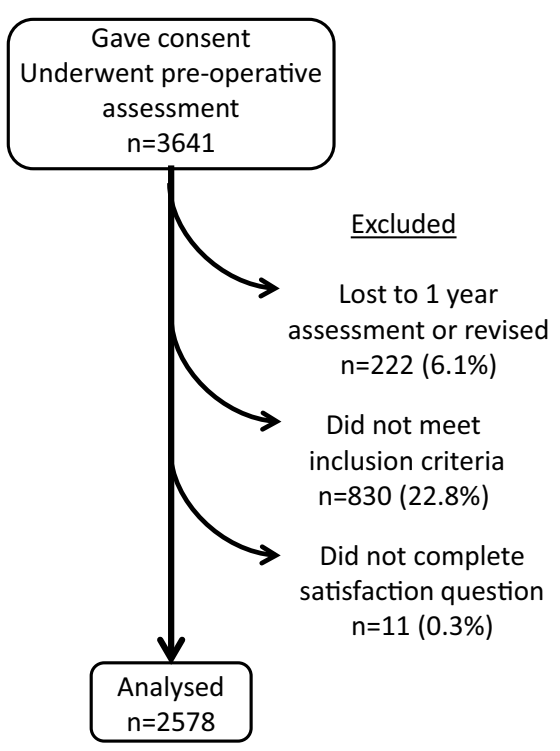

The original article can be found online at https://doi.org/10.1007/ s00167-018-4879-5.

Lucy C. Walker

lcwalker86@gmail.com

Nick D. Clement

nickclement@doctors.org

Michelle Bardgett

michelle.bardgett@nuth.nhs.uk

David Weir

david.weir@nuth.nhs.uk

Jim Holland

jim.holland@nuth.nhs.uk

Craig Gerrand

craig.gerrand@nuth.nhs.uk

David J. Deehan

deehan1@ hotmail.co.uk

1 Department of Orthopaedics, Newcastle-upon-Tyne

University Hospitals Foundation Trust,

Freeman Hospital, Freeman Road, High Heaton,

Newcastle upon Tyne NE7 7DD, UK 